\title{
Data information as a new subject matter of IP: What can China learn from Europe?
}

\author{
Wentao Zhang \\ Intellectual Property Rights Research Institute of Xiamen University, Xiamen, 361005, China \\ zwt7129@126.com
}

Keywords: Data information, Industrial data, Intellectual property, Trade secret.

\begin{abstract}
The research is constructed on three layers of questions. The first layer of questions is concerning the conceptual aspect of data. In this regard, I will explore the nature of data and analyze the existence in legal system. Then a conclusion will be made on if "data information" is a proper concept in lawmaking in China. The second layer of questions relates to the justification or falsification of protecting industrial data with exclusive rights. As a potential object of intellectual property rights, both legal and economic theories will be used to examine whether industrial data should be bonded with exclusive rights by law, especially under the context of China. The third layer concerns the methodological questions, regarding to the approach of constructing a systematic legal protection for industrial data. Even if the protection industrial data is justified, questions still exist concerning to the means of protection. Different approaches of protection lead to very different consequences and a more reliable solution may be found not only from the experience of jurisdictions such as EU and US, but also from legal theories. Based on this structure of research, a relatively complete conclusion may be drawn for the regulation of "data information" and industrial data protection.
\end{abstract}

\section{Introduction}

The concepts of "data information" and "virtual property" have been abandoned in the latest version of draft of Chinese Civil Code (General part) and lawmakers have become more cautious about the legislation for data.

However, considering that data itself has increasingly become more valuable and it has already given rise to a large scale of dispute, a deep research related to data protection will still be beneficial for China as well. Against this background, my research is going to analyze whether "data information" should be protected as a new subject matter of intellectual property; if not, how should lawmakers design the legal realm for "data information" and response to newly emerged data such as industrial data.

\section{Realizing the Nature of Data and Its Formality in Legal System}

In the amendment of civil law in China, the concept so called "data information" is doubtful and the draft itself has not given out a clear definition for it yet. Since each kind of the subjects of intellectual property rights could be regarded as certain kind of "information" 1 and data itself is certainly a kind of "information", thus the word "information" - in the conception of "data information" - seems to be redundant.

Moreover, this concept will mislead the realization of the nature of data. The variety and diversity of data make the definition over enormous that all kinds of data may be included in, such as raw data, personal data, industrial data, database and so on. If data is the certain object that civil law tends to

\footnotetext{
${ }^{1}$ E.g. Peter Drahos regards intellectual property as property rights in information. See Drahos P. Global property rights in information: the story of TRIPS at the GATT[J]. Prometheus, 1995, 13(1): 6-19. Also see Drahos P, Braithwaite J. Information feudalism: Who owns the knowledge economy?[M]. Earthscan, 2002. A scholar also categories different intellectual property rights into corresponding types of information, based on a method of induction. See Herbert Zech. Information as Property[J], JIPITEC 6 (3) 2015, p. 192.
} 
grant an exclusive right to it, the realization of data should be the foundation of legislation. A blurry definition will be no good for this purpose.

Then the question is how we can realize data in a systematic way, so that it can provide some insights in comparing with other immaterial objects. Semiotics may be effective in exploring the nature of data. According to semiotic theories, information can be divided into three levels, from low to high levels, they are: syntactic information, semantic information and pragmatic information. ${ }^{2}$ In short, syntactic information refers to the information of signs (like 0 and 1); semantic information refers to the information of meanings; and pragmatic information refers to the goals of information. Higher level of information is based upon the lower ones.

Data should be classified to the syntactic information under this structure which is the lowest level. ${ }^{3}$ However, other kinds of IP right objects such as work, trademark and invention are normally classified to the semantic and pragmatic information. ${ }^{4}$ Consequently, if data is protected as an IP rights, the existence of other kind of IP rights will definitely be affected.

If we change the angle of observation, it could be found that in the legal system, information exists in many kinds of formalities. Despite IP rights protected objects, information could also exists as privacy and certain kinds of property. As the most foundational level of information, data could actually become any formality which is mentioned above.

Based on this theory, the concept of "data information" as a new subject matter of IP rights is totally falsified.

\section{Understanding the Benefits and Problems of Granting Industrial Data with Exclusive Right}

Data without further classification may not be possible to be protected by law, not to mention being treated as a property right. ${ }^{5}$ There already exists a rough classification of data, i.e. personal data and non-personal data. Generally, personal data is usually believed to be not suitable for being protected as an intellectual property, ${ }^{6}$ while non-personal data is believed to have the potential to be protected as IP rights. However, the concept and scope of non-personal data is also not well defined. A better concept for discussion is industrial data, which is the data sensored, produced, aggregated and distributed by machine.

Regarding to grant a new IP rights to industrial data, it may have both benefits and problems. The possible benefits may be providing incentives for the production an disclosure of industrial data as well as maintaining competition order in relevant markets. ${ }^{7}$

However, these benefits are uncertain. For example, the presumption of IP rights to provide incentive of production and investment is based upon the fact that the the specific subject of IP rights is a kind of public goods. For the characteristics of public goods, the owner of the subject will suffer the cost of other's copying and using if he cannot exclude these behaviors. The problem for industrial data is that the owner of it can actually exclude others access to it by technological methods or keep it as a secret. As a result, industrial data will not really suffer the problems that public goods have and the exclusive IP right will not bring the incentive as promised. ${ }^{8}$

\footnotetext{
${ }^{2}$ See Carnap R. Introduction to semantics[M]. Cambridge, Massachusetts: Harvard University Press, 1948.

${ }^{3}$ Wiebe A. Protection of industrial data-a new property right for the digital economy?[J] Journal of Intellectual Property Law \& Practice, 2016,175.

${ }^{4}$ Zech H, Information as Property, JIPITEC, 2015(6), 192.

${ }^{5}$ Maximilian Becker. Schwerpunkt: Rechte an Industrial Data und die DSM-Strategie[J], GRUR Newsletter, 2016(01), p. 7. Available at: http://www.grur.org/uploads/media/2016-01_GRUR_Newsletter_01.pdf

6 "Granting individuals property rights in personal information is unlikely to achieve information privacy goals in part because a key mechanism of property law, namely the general policy favoring free alienability of such rights, would more likely defeat than achieve information privacy goals." See Samuelson P. Privacy as intellectual property?[J]. Stanford Law Review, 2000: 1125-1173.

${ }^{7}$ Wiebe A. Protection of industrial data-a new property right for the digital economy?[J] Journal of Intellectual Property Law \& Practice, 2016,175.

${ }^{8}$ Kerber W. A New (Intellectual) Property Right for Non-Personal Data? An Economic Analysis[J], Gewerblicher Rechtsschutz und Urheberrecht, Internationaler Teil (GRUR Int), 11/2016
} 
Meanwhile, granting exclusive rights to industrial right may encounter with some problems. These problems often include allocation, specification and access problems. Allocation problem refers to the question who owns industrial data. In the digital environment, many stakeholders are involved in the production, aggregation and distribution of data. It is due to machines (such as networked cars) are normally manufactured, used or owned by different stakeholder. Thus the allocation of rights among these stakeholders may be a very complicated problem. Specification problem is mainly due to the particularity of industrial data. Since industrial data is more likely to be a syntactic information rather than semantic or pragmatic information (current subject matter of IP rights are all belong the later classification), the scope of the potential rights of industrial must be very different from current IP rights. The designation and enforce of such right will be complicated and full of uncertainty. Access problem is the last but also most important problem raised from granting exclusive rights. An obvious consequence that granting exclusive rights to industrial will lead to, is the increasing barriers to accessing data as well as entering the related market. This consequence will definitely affect the legitimacy of industrial data protection.

\section{Concluding The System Constructed By IP Law and Unfair Competition Law for Newly Emerged Subject}

Finding a basic methodology to deal with newly emerged subject matter is very important for developing countries like China. There are mainly four main types of protection for subject matter related to the development of digital technology, which are intellectual property, unfair competition, contracts and technological protection measures (TPMs). ${ }^{9}$

Regarding to non-creative database, a sui generis right is considered to be the most effective mean of protection which directly grant right holder an exclusive property right ${ }^{10}$ and EU had established a sui generis right regime to achieve such effective protection. On the contrary, the U.S. did not take the same strategy. Accordingly, database protection in EU with the extra sui generis right system is much stronger than it in the U.S. However, despite the stronger protection, a report from EU Commission shows, "the ratio of European/US database production, which was nearly 1:2 in 1996, has become 1:3 in 2004." 11 The conclusion for database case suggests that stronger protection may not certainly lead to better market efficiency.

Even more seriously, although the EU commission has already recognized this problem, the protection is still not repealed from database. As professor Kur comments, "This conforms to a general pattern which can be observed throughout intellectual property law: Once protection has been granted for certain types of items or achievements, or when existing protection is extended in its scope, it will never be "scaled back" to the status quo ante." 12

There are several ways for protecting investment in intangible object from legal perspective and they can be divided into different levels of density according to professor Hilty's theory. From weak to strong, they are protection based on open-ended norms such as general clauses; sui generis rights; trade mark rights, industrial designs, and geographical indications; and lastly patents and copyright. ${ }^{13}$ Based on this model, professor Kur suggests new type of protection should start from small use unfair competition law as an "incubator" for new types of rights and gradually enhance the protection towards exclusive right if it is necessary. ${ }^{14}$ Based on previous experiences, the protection for industrial data should start from lowest level and gradually grow if it is necessary.

\footnotetext{
${ }^{9}$ Derclaye E. The legal protection of databases: a comparative analysis[M]. Edward Elgar Publishing, $2008: 9$.

10 "the burden is regularly shifted to the alleged infringer to justify her conduct once the prerequisites for protection have been established, whereas - at least according to the general theory - it is the person alleging that another's activities are unfair, who must bear the onus of pleading and substantiating the claim." Kur A. What to Protect, and How? Unfair Competition, Intellectual Property, or Protection Sui Generis[J]. In: Intellectual property, unfair competition and publicity: convergences and development/ed. by Nari Lee et al.-Cheltenham: Elgar, $2014: 21$.

${ }^{11}$ See DC Internal Market and Services Working Paper, supra, fn. 8.

${ }^{12}$ Kur A. supra, fn. 10, p. 27.

${ }^{13}$ See Hilty R M. The law against unfair competition and its interfaces [J], in R.Hilty and F. Henning-Bodewig (eds.), Law Against Unfair Competition - Towards a New Paradigm in Europe? 2007: 1-52.

${ }^{14}$ See Kur A. supra, fn. 10, pp. 11-32.
} 


\section{References}

[1]. Becker, M. "Schwerpunkt: Rechte an Industrial Data und die DSM-Strategie" (2016)01 GRUR Newsletter 7. Available at: http://www.grur.org/uploads/media/2016-01_ GRUR_ Newsletter 01.pdf

[2]. Bergelson, V. "It's personal but is it mine? Toward property rights in personal information" (2003) UC Davis Law Review, 37(379).

[3]. Crompvoets, J., De Man, E. \& Geudens, T. "Value of Spatial Data: Networked Performance beyond Economic Rhetoric" (2010) 5 Int. J. of Spatial Data Infrastructures Research 96.

[4]. Hilty, R.M. "The law against unfair competition and its interfaces" 2007, in R.Hilty \& F. Henning-Bodewig (eds.), Law against Unfair Competition - Towards a New Paradigm in Europe? 1.

[5]. Karnell, G. W. "The European Sui generis Protection of Databases" (2002) J. Copyright Soc. of the USA 994.

[6]. Kur, A. "What to Protect, and How? Unfair Competition, Intellectual Property, or Protection Sui Generis" (2014). In: Intellectual property, unfair competition and publicity: convergences and development/ed. by Nari Lee et al.-Cheltenham: Elgar 21.

[7]. Reichman, J.H. \& Samuelson, P. "Intellectual property rights in data" (1997)50 Vand. L. Rev. 49.

[8]. [Samuelson, P. "Privacy as intellectual property?" (2000) Stanford Law Review 1125.

[9]. Schwartz, P. M "Property, privacy, and personal data" (2004) Harvard Law Review, 2056-2128.

[10]. Smith, L.J. Doldirina, C. "Moving Space Data towards Public Good" (2008)24 Space Policy 22.

[11]. Stallkamp, L.E. "Remote Sensing Data as a Public Good" (2000) Remote Sensing Law and Policy 575.

[12]. Surblyte G. Data Mobility at the Intersection of Data, Trade Secret Protection and the Mobility of Employees in the Digital Economy. Max Planck Institute for Innovation \& Competition Research Paper, (2016) (16-03).

[13]. Surblyte G. Data as a Digital Resource. Max Planck Institute for Innovation \& Competition Research Paper, (2016) (16-12).

[14]. Wiebe A. Protection of industrial data-a new property right for the digital economy? Journal of Intellectual Property Law \& Practice, (2016), 175.

[15]. Wagner, R.P. "Information Wants to Be Free” (2003) 103 Colum. Law. Rev. 995.

[16]. Herbert Zech, Information as Property, 6 (2015) JIPITEC 192, para 1. 